\title{
MÍDIAS SOCIAIS DIGITAIS E NARRATIVAS DE RESISTÊNCIA NO ESPAÇO ESCOLAR
}

\author{
Nívea Rohling* \\ Maria de Lourdes Rossi Remenche** \\ Universidade Tecnológica Federal do Paraná \\ Departamento Acadêmico de Linguagem e Comunicação \\ Curitiba, PR, Brasil \\ Nelita Bortolotto*** \\ Universidade Federal de Santa Catarina \\ Centro de Ciências da Educação \\ Departamento de Metodologia de Ensino \\ Florianópolis, SC, Brasil
}

\begin{abstract}
Resumo: Este artigo focaliza a análise de cartazes de manifestação que tematizam um evento discursivo-político específico, a saber, a ocupação de escolas públicas de São Paulo (Brasil) por estudantes secundaristas, ocorrida em 2015. Observa o modo como esses enunciados, com tonalidade de protesto e resistência, produzem sentidos e constroem novas narrativas sobre ser estudante secundarista na escola pública brasileira de hoje. A análise ancora-se teórica e metodologicamente nos estudos do Círculo de Bakhtin, sobretudo em conceitos como discurso, enunciado, cronotopo e horizonte apreciativo. Os resultados mostram que, nesse evento particular, os enunciados de estudantes secundaristas marcam valorativamente, pelo tom de resistência e empoderamento, vozes do presente que postulam um futuro não absoluto e demarcado. Pelo vivenciamento de uma prática social não indiferente, se abrem para a produção de uma narrativa outra, despontando, por formas de comunicação ideológica, outro horizonte social, outra realidade de esfera coletiva.
\end{abstract}

Palavras-chave: Discurso. Mídia. Escola Pública. Manifestação. Resistência.

1 INTRODUÇÃO

O impacto social da ocupação de escolas públicas no Estado de São Paulo, ocorridas em novembro de 2015 e que se estendeu para demais estados do Brasil em 2016, ficou evidenciado, em grande escala, como movimento estudantil de vivenciamento da crítica

\footnotetext{
* Doutora em Linguística pela Universidade Federal de Santa Catarina - UFSC. Docente do Programa de Pós-Graduação em Estudos de Linguagens. E-mail: nivear@utfpr.edu.br.

** Doutora em Linguística pela Faculdade de Filosofia e Letras da Universidade de São Paulo. Docente da Universidade Tecnológica Federal do Paraná (UTFPR-Curitiba). Docente do Programa de Pós-Graduação em Estudos de Linguagens. E-mail: mremenche@utfpr.edu.br.

*** Pós-doutora pela Universidade Estadual de Campinas - São Paulo - UNICAMP; Doutora pela Universidade Federal de Santa Catarina - UFSC. Coordenadora do Núcleo de Estudos e Pesquisas em Alfabetização e Ensino da Língua Portuguesa (NEPALP). E-mail: nelita.bortolotto@ufsc.br.
}

ROHLING, Nívea; REMENCHE, Maria de Lourdes Rossi; BORTOLOTTO, Nelita. Mídias sociais digitais e narrativas de resistência no espaço escolar. Linguagem em (Dis)curso - LemD, Tubarão, SC, v. 18, n. 2, p. 413-429, maio/ago. 2018. 
pela atitude de ocupação de um espaço social e democrático, objetivando a publicização de vozes contrárias ao discurso oficial do governo vigente. Essa abertura, porém, não se circunscreveu àquele ambiente. Agregada a essa ação, as vozes foram expandidas em diversos perfis criados em redes sociais a fim de dilatar a escuta da "não aceitação" por parte dos estudantes e da comunidade implicada, quanto às medidas de reorganização do sistema escolar no Estado de São Paulo.

As ocupações foram uma resposta ao projeto de reorganização das escolas públicas estaduais, proposto pelo Governo do Estado de São Paulo, e anunciado em setembro de 2015, que pretendia fechar cerca de 90 escolas, bem como agrupá-las por níveis de ensino, o que afetaria 300 mil estudantes. Tendo em vista o movimento de ocupação das escolas ${ }^{1}$ e toda a pressão política decorrente do movimento dos estudantes, o Governo Estadual assinou a revogação da reorganização escolar em quatro de dezembro de 2015.

O anúncio de tais medidas gerou, por conseguinte, uma série de manifestações por parte da comunidade escolar, cujo ponto culminante foi a ocupação de escolas por estudantes, como forma de protesto em relação ao referido projeto de reorganização, evidenciando a necessidade de publicização de vozes contrárias ao discurso oficial. É nesse contexto que cartazes de protestos circularam de modo recorrente nas redes sociais digitais. Um contexto discursivo tenso e conflituoso produziu ações protagonistas não só nos espaços públicos como a escola ou as ruas, mas também, como mencionado, na criação de perfis em diferentes redes sociais digitais, como "Não fechem minha escola", por exemplo, possibilitando a interação com diferentes discursos e a materialização de projetos de dizer que foram constituindo narrativas sobre diferentes objetos de discursos: os significados de ser estudante, da luta em foco, sobre a escola pública, para citar poucos exemplos.

As redes sociais digitais, em sua configuração particular, explicitaram a emergência de produção e de circulação de enunciados de protesto (contrapalavra), portanto, situações de enfrentamento, lutas políticas e ideológicas. Evidenciou-se, assim, o potencial dessas redes sociais de se constituírem como espaços contemporâneos para publicizar a produção dos próprios sujeitos envolvidos no evento como alternativa a outras mídias como, por exemplo, jornais e revistas, pertencentes às grandes empresas de comunicação que, por vezes, corroboram os interesses de uma classe hegemônica representante do discurso oficial.

Esse domínio discursivo mostra-se produtivo e instigante para os estudos da linguagem, em que se evidenciam outras formas de perceber os espaços públicos e as ações protagonistas dos sujeitos, sobretudo, como é o caso aqui, na escola pública brasileira.

Dessa forma, neste texto ${ }^{2}$, a partir da análise de enunciados veiculados nas redes sociais, buscou-se problematizar os modos como as redes sociais digitais contribuem para

\footnotetext{
${ }^{1}$ No total foram 196 escolas ocupadas desde nove de novembro de 2015. Os estudantes ocupram as escolas com objetivo de protestar contra a reorganização proposta pelo Governo Estadual, segundo informação disponível em: <http://g1.globo.com/sao-paulo/escolas-ocupadas/noticia/2015/12/vamos-dialogar-escolapor-escola-diz-alckmin.html>. Acesso em: 28/05/2018.

${ }^{2}$ Este artigo é resultado das ações de pesquisa do Grupo de Pesquisa em Linguística Aplicada (GRUPLA), da UTFPR/Curitiba.
} 
a ressignificação das práticas de linguagem e vêm se configurando como um importante espaço público de embate de vozes, bem como lócus de construção de narrativas figuradas pelos alunos de escola pública. Ainda mais, considerando que na contemporaneidade as mídias sociais digitais vêm ampliando contornos, mas também, por vezes, borrando espaços de representação, como ocorre, por exemplo, na explicitação de acontecimentos no espaço escolar.

Para tanto, foram selecionados cartazes de manifestação, postados na rede social Facebook, que materializam gêneros discursivos, constituindo narrativas sobre o espaço escolar e sobre o que significa ser estudante da escola pública brasileira na contemporaneidade. Certamente, tais narrativas não decorrem de percepção momentânea e impulsiva como indivíduo (estudante) ou como coletivo (comunidade estudantil), mas advêm da constituição de uma percepção histórica, social e cultural - não indiferente -, presente, acumulada e aprofundada no tempo histórico real de cada sujeito-estudante e como coletividade (pelas vivências socioculturais partilhadas). As narrativas fixadas em enunciados publicizados em cartazes apresentam uma voz-outra, a da contrapalavra exposta no todo ou em parte particular, uma "voz-livre", uma "voz-protesto", uma vozque-grita pela escuta. Mas, que movimento foi/é esse que impulsiona/impulsionou o protesto? Que encoraja um "outro-dizer", o dizer da contrapalavra diante do poder do Estado?

A narrativa particular da experiência de ocupações em cartazes em redes sociais se lança como elemento fecundo para a compreensão do presente momento e do passado histórico, pois por ela é possível pensar as relações dialógicas como potência que pode/poderia levar a muitas direções. Conceitos da teoria do dialogismo de Bakhtin e Círculo (BAKHTIN, 1998; 2003; 2015; VOLOCHÍNOV, 2013) como de linguagem, discurso e enunciado, cronotopia, ${ }^{3}$ orientam a análise ao distanciar-se de compreensões as quais endossam o entendimento do tempo presente como provindo do que antes sucedeu (do passado ao futuro). Bakhtin defende a tese da noção do tempo como simultaneidade (coexistência e interação/ tempo histórico real e percepção do devir). Machado (1998), interpretando Bakhtin, expõe:

\begin{abstract}
Para Bakhtin, tanto na vida como na literatura, o tempo se organiza mediante convenções que não se restringem a definir o movimento e o arranjo das situações; pelo contrário, firmam posicionamentos e revelam diferentes formas de ver o mundo. Em seus estudos sobre o tempo existe a busca do dimensionamento entre ética e estética na criação. A narrativa torna-se um campo fértil de investigação pois nela se constituem os discursos sobre o mundo a partir dos quais é possível pensar as relações dialógicas”. (p.34)
\end{abstract}

Outro caminho teórico que se encadeia à análise das narrativas estudantis em cartazes, diz respeito a estudos sobre mídias, mídias sociais e redes sociais (SILVERSTONE, 2005, STAM, 2010, ARAÚJO, 2016) a fim de corroborar a análise proposta.

\footnotetext{
${ }^{3}$ Neste trabalho não inserimos uma exposição detalhada sobre esses conceitos do âmbito da elaboração teórica bakhtiniana, tendo em vista os diversos trabalhos de comentadores da teoria já publicados na área de estudos da linguagem.
} 
Nesse cenário, apresenta-se, a seguir breve percurso de perspectivas conceituais de autores que se ocupam de estudos linguagem, mídia e cultura acerca dessa particularidade que é a produção de sentidos nos encontros sociais voltados a instâncias públicas da comunicação humana. Na sequência, aborda-se as manifestações estudantis na ocupação de escolas públicas, analisando a produção de discursos desse público em redes sociais, os quais se inscrevem no espaço midiático como forma de luta e resistência política por direitos à educação. Na última parte, são apresentadas as regularidades observadas no processo de análise dos dados e o que dessa análise se evidencia como voz que postula um futuro não absoluto e demarcado, mas como acontecimento, onde vivências e sonhos outros se insinuam como possíveis.

\section{MÍDIA, TECNOLOGIA E IDEOLOGIA}

As mídias se apresentam como mediadoras das relações sociais e vêm assumido um papel significativo na configuração da cultura pós-moderna ${ }^{4}$. Sobre esse tema, Silverstone (2005) posiciona-se criticamente ao afirmar que a mídia tem sido propagada como extensão do homem, tal como propõe a visão de Marshall McLuhan: “[...] como próteses, que aumentam o poder e a influência, mas que talvez nos incapacitam como nos capacitam, enquanto nós, objetos e sujeitos da mídia, nos enredamos mais e mais no profilaticamente social." (SILVERSTONE, 2005, p. 16). Essa visão de mídia como extensão do corpo tende, de acordo com Silverstone (2005), a tornar tênue a fronteira entre o humano e o técnico, entre o corpo e a máquina. Isso implica uma perspectiva de completo domínio da mídia sobre o homem e leva-nos a pensar que vivemos em espaços totalmente simbólicos, autorreferenciais que proporcionam apenas a reprodução e nunca o original. Assim, a mídia se torna a medida de todas as coisas no espaço onde vivemos e transitamos.

Em contraposição a essa visão, digamos, determinista sobre mídia, Silverstone (2005, p. 26) também afirma que é possível estabelecer um distanciamento de reflexão entre as experiências na mídia e fora dela: "Podemos distinguir, e de fato distinguimos, fantasia de realidade, podemos preservar, e de fato preservamos, alguma distância crítica entre nós e a mídia [...]". Essa proposição do autor aproxima-se da noção bakhtiniana de sujeito responsivo e responsável e que apresenta resistência, uma vez que, nessa perspectiva epistemológica, o sujeito não tem álibi para sua existência, não tem álibi para não ocupar o seu lugar único e irrepetível; nesse lugar, o sujeito responde ativamente.

Ao problematizar as relações entre conteúdo vivido e conteúdo abstrato, Bakhtin propõe que o ato é gesto ético no qual o sujeito se revela, arrisca-se e também se responsabiliza pelo pensamento (BAKHTIN, 2010[1986]). Essa concepção trata do nãoálibi do existir, pois o lugar que ocupo não pode ser ocupado por outro e desse lugar que é ocupado por mim, devo agir responsavelmente. Afinal o que precisa ser feito por um sujeito não pode ser feito por mais ninguém. Com essa tese, Bakhtin enfatiza a posição ética a ser ocupada pelo sujeito no mundo, que se constitui nas relações de alteridade.

\footnotetext{
${ }^{4}$ Pós-modernidade aqui entendida tal qual Hall, como o período da segunda metade do século XX, em que se destacam várias mudanças socioculturais, que vêm fragmentando as noções de gênero, raça, identidade, dentre elas o processo de globalização (HALL, 2006). Na visão de Hall, as sociedades pós-modernas caracterizam-se pela diferença: "são atravessadas por diferentes divisões e antagonismos sociais que produzem uma variedade de diferentes 'posições de sujeito'. (HALL, 2006, p.14).
} 
A cultura humana - a ciência, a arte e a vida -, sustenta o autor, "só adquirem unidade no indivíduo que os incorpora à sua própria unidade." (BAKHTIN, 2003, p. XXXIII). Na linha dessa sua tese, Bakhtin indaga e observa, mas "o que garante o nexo interno entre os elementos do indivíduo [arte/vida]? Só a unidade da responsabilidade. Pelo que vivenciei e compreendi na arte, devo responder com a minha vida para que todo o vivenciado e compreendido nela não permaneçam inativos.”.

Stam (2010), ao propor uma abordagem crítica da mídia, afirma que as concepções sobre a mídia oscilaram entre a melancolia pessimista e a euforia exagerada. Para os pessimistas, a mídia foi concebida como um instrumento de reificação capitalista, um aparato opressivo, uma máquina de influenciar que prova pouca resistência. Contrariamente, há os que a olham de forma entusiasta, saúdam o impacto revolucionário das técnicas modernas de reprodução ou a subversão midiática dos tradicionais privilégios da elite literária (STAM, 2010).

Nessa relação polarizada e pouco produtiva de esboçar uma crítica midiática, conforme Stam (2010), ainda que nos escritos do Círculo de Bakhtin não se tenha discutido diretamente as políticas culturais dos meios de comunicação de massa, a teorização do Círculo pode ser considerada producente para tal discussão. Para Stam, a mídia de massa pode ser conceituada, numa perspectiva bakhtiniana, como "uma rede complexa de signos ideológicos, situada no interior de ambientes múltiplos - o ambiente gerador dos meios de comunicação, o ambiente gerador ideológico mais amplo, e o ambiente socioeconômico - cada um com as próprias especificidades" (STAM, 2010, p. 333). Apresentar os estudos bakhtinianos como crítica produtiva para abordar a mídia na cultura humana demanda pensar na contribuição de dois outros conceitos abarcados pela teoria bakhtiniana, o de forças centrípetas e o de forças centrífugas. Demanda pensar no jogo dessas duas forças, as centrípetas e as forças centrífugas, tendendo a resultados para um ou para o outro lado. Na visão de Stam, pode-se dizer que, na mídia de massa, existem padrões de supremacia, tendências ideológicas, mas a dominação nunca é completa ${ }^{5}$ :

[...] não existe nenhum texto unitário, nenhum produtor unitário, e nenhum espectador unitário; em vez disso, existe uma heteroglossia conflituosa que permeia o produtor, o texto, o contexto, e o leitor-observador. Cada categoria é atravessada pelo centrípeto e pelo centrífugo, o hegemônico e o antagônico. (STAM, 2010, p. 334).

Nos embates entre as forças centrípetas e as forças centrífugas, a mídia atua na construção de representações que os sujeitos criam do mundo. Nesse sentido, é preciso que a reflexão sobre a mídia se estenda para além de seu caráter de simples artefato tecnológico que possibilita reflexos consensuais da cultura, uma vez que é um elemento importante na constituição de discursos e nas representações socialmente construídas. Isso porque as mídias agem intrinsecamente nas novas possibilidades de interagir e, por conseguinte, na produção e circulação de discursos, no surgimento de novos gêneros discursivos, sobretudo os gêneros produzidos nos espaços digitais, enfim em outras

\footnotetext{
${ }^{5}$ Nessa passagem do texto de Stam há uma intrínseca relação com a concepção de ideologia do Círculo de Bakhtin. A ideologia oficial não domina irrestritamente, ela se constitui na relação com as ideologias do cotidiano e nos embates entre forças centrípetas e forças centrífugas.
} 
possibilidades de uso da linguagem que nascem nessas novas interações midiáticas. Bakhtin, em um contexto histórico diferente do nosso ${ }^{6}$, já salientava o papel relevante da criação da imprensa, uma mídia, para a constituição do romance como gênero. Tal perspectiva aponta para a relação imbricada entre as atividades humanas e a produção de discurso, evidenciando que são as variadas atividades humanas que propiciam a constituição e circulação de discursos.

Geraldi $(2010)^{7}$, no que tange à discussão sobre linguagem e tecnologia, de forma geral, aponta como produtivo o fato de as tecnologias digitais trazerem consigo o direito de expressão a qualquer um, ou seja, o direito de dizer. As tecnologias possibilitam que a palavra em rede possa alcançar interlocutores diversos. Esse estado de coisas, segundo o pesquisador, instaura uma nova ética da responsividade nas relações virtuais, o que implica novas relações no campo da ética.

Assim é que as mídias, sobretudo as mídias sociais digitais são artefatos que compõem sistemas de significados na produção de identidades e subjetividades, sendo, pois, um espaço fluido de entrelaçamentos e possibilidades de representação.

\section{PRODUÇÃO E CIRCULAÇÃO DE CARTAZES DE MANIFESTAÇÕES DA OCUPAÇÃO DE ESCOLAS PÚBLICAS}

Como unidade representativa dos dados analisados, foram selecionados dois enunciados $^{8}$ de cartazes de manifestações que, ao mesmo passo que ocupam, de modo físico, o espaço escolar e as ruas no entorno da escola, são postados em perfis de redes sociais e têm uma ampla visualização. Segundo Magalhães e Queijo (2015) ${ }^{9}$, os cartazes capturam metonimicamente os discursos estruturantes dos eventos.

Primeiramente, é preciso considerar a situação de produção e circulação desses enunciados. Como já mencionado neste trabalho, os cartazes foram produzidos em um evento discursivo concebido como atos da ocupação das escolas públicas de São Paulo (Brasil) no ano de 2015.

O espaço específico da postagem foi o perfil da rede Facebook intitulado: "Não fechem minha escola" ${ }^{10}$. Essa escolha se deu em virtude da representatividade em termos de participantes e porque os objetos discursivos tematizados, neste grupo, referem-se ao evento em foco na discussão - o movimento das ocupações nas escolas de São Paulo. A rede social em que o grupo está inserido, Facebook, permite que seus interlocutores, por

\footnotetext{
${ }^{6}$ As elaborações teóricas do Círculo se deram no período de 1919 a 1929, em meio a um conturbado contexto político-social russo, em que ainda se tinha como centro a mídia impressa.

${ }^{7}$ Palestra proferida pelo pesquisador no "Círculo Rodas de Conversa Bakhtiniana", em novembro de 2010 na UFSCar, cujo título é "Onde o ético e o estético se encontram hoje".

${ }^{8}$ Foi analisado um conjunto de 10 (dez) cartazes de manifestação, postados na página "Não fechem minha escola" no período da ocupação das escolas em São Paulo. No entanto, em virtude da necessidade de delimitação, selecionamos somente dois enunciados para exemplificação da análise desenvolvida.

${ }^{9}$ Os autores analisam cartazes das manifestações populares ocorridas no Brasil em 2013 o que, segundo asseveram, desencadeia um tipo de ativismo não convencional.

${ }^{10}$ Disponível em: <https://www.facebook.com/naofechemminhaescola/?fref=ts>.
} 
intermédio de seus perfis pessoais, participem das discussões que acontecem por meio de postagens e comentários, potencializando uma relação interlocutiva semelhante à de fóruns de discussão online.

O grupo é público, o que significa dizer que qualquer pessoa, mesmo não sendo da comunidade escolar, pode ler as postagens e interagir nesse espaço discursivo. Embora possibilite uma ampla participação e publicização de seus conteúdos, a descrição do grupo afirma que se trata de um site educacional e aponta para uma linha temática ao propor que o tema é "Contra a absurda "reestruturação" das escolas, todo apoio às ocupações!\#respeiteminhaescola”. Nesse apontamento temático já se mostra saliente a entonação de luta e de protesto materializada na seleção lexical de adjetivos como Contra, absurda, ou, ainda no uso do imperativo na hashtag - "\#respeiteminhaescola".

É relevante destacar que essa página também se revela como uma resposta-ativa (reação-resposta) ao ser criada para divulgar o movimento de ocupação da escola, constituindo um espaço de informação e debate dos eventos que compõem o movimento.

Do ponto de vista de uma análise dialógica, é possível considerar a totalidade dessas ocupações como uma arena discursiva; nessa condição, as manifestações guardam um caráter de tensão entre o discurso oficial e o não oficial, que permite identificar aspectos de carnavalização no modo como se articula (GUIMARÃES; QUEIJO, 2015, p. 170). Isso requer pensar em como a circulação em rede - aparato técnico - altera os dizeres dimensão narrativa cotidiana de enunciados concretos - com ares carnavalescos dimensão metanarrativa, que se dá no grande tempo (2015, p. 175). Magalhães e Queijo (2015, p. 169) questionam: "como a circulação em páginas da internet segmenta e altera a potencialidade semântica desses enunciados?", referindo-se aos cartazes de manifestação que são publicizados na rede.

Assim, esses textos saem da escola, seu lugar de produção e circulação mais imediato, e ganham o espaço midiático. Com a circulação do discurso nesse outro espaço comunicativo, certos problemas metodológicos, caso seja mobilizada a noção bakhtiniana de cronotopo, se evidenciam. Então, algumas perguntas surgem: depois de publicizados nas redes sociais digitais e compartilhados em perfis pessoais, esses enunciados deixam de pertencer ao espaço institucional escolar? ou, o fato de serem publicizados nesse espaço midiático constitui uma espécie de extensão da esfera escolar? Seria uma relação de hibridismo ${ }^{11}$ de cronotopo?

Certamente, é possível afiançar o entendimento das redes sociais digitais como um espaço em que discursos produzidos por diferentes esferas de atividades humanas se encontram e coabitam em uma existência híbrida. Por oportuno, vale apontar a posição de Araújo (2016, p. 52) que considera a Web "um ambiente plural de profundo poder de absorção que transmuta para si diversas esferas de atividade humana [...]”. O autor não

\footnotetext{
${ }^{11} \mathrm{O}$ termo hibridismo tem ancoragem em Bakhtin (2015), quando tematiza o híbrido entre linguagens e as hibridações nas práticas assentadas na cultura. Canclini (2013) também mobiliza o termo hibridação para se referir aos processos socioculturais nas quais estruturas ou práticas discretas, que existiam de forma separadas, se combinam para gerar novas estruturas, objetos e práticas (p. XIX).

${ }^{12}$ Neste texto, o autor investiga gêneros discursivos em redes sociais digitais, focalizando a análise de dados do Twitter a fim de discutir os processos de reelaboração de gêneros, que emergem das relações entre linguagem e tecnologia.
} 
concebe as redes sociais digitais ou a própria Web como uma instância discursiva, mas sim como ambientes que abrigam os discursos e gêneros, provocando neles alterações decorrentes das diferentes apropriações sociais da tecnologia pelos indivíduos (ARAÚJO, 2016).

Podemos dizer, por certo, que, ao serem publicizados nas redes sociais digitais, os cartazes ampliam seu espaço de circulação e empoderam o movimento, pois sujeitos assumem o lugar de atores sociais nesse tempo-espaço de resistência, assumindo a atividade crítica, como ativismo, isto é, como "atividade enérgica" dirigida a um objeto discursivo, um ativismo construído socialmente ao longo da história e da cultura humana e não como um fenômeno individual ou pontual -, de uma época e para uma época específica $^{13}$. Desse modo, os enunciados em cartazes apresentam, arriscamos dizer, um ativismo outro, pelo modo de o estudante secundarista da escola pública se posicionar na cena enunciativa, empenhando-se em outra lida de narrativas de empoderamento e resistência. Pode-se observar deslocamentos dos projetos de dizer na escola (dos dizeres pedagógicos), marcados, agora, nesse espaço-tempo, pelo protagonismo juvenil (ativismo político).

Na figura 1 a seguir é apresentada uma imagem da página inicial do perfil no Facebook "Não fechem minha escola", atualizada em 31/10/2017:

\section{Figura 1 - Página inicial do perfil no Facebook "Não fechem minha escola".}

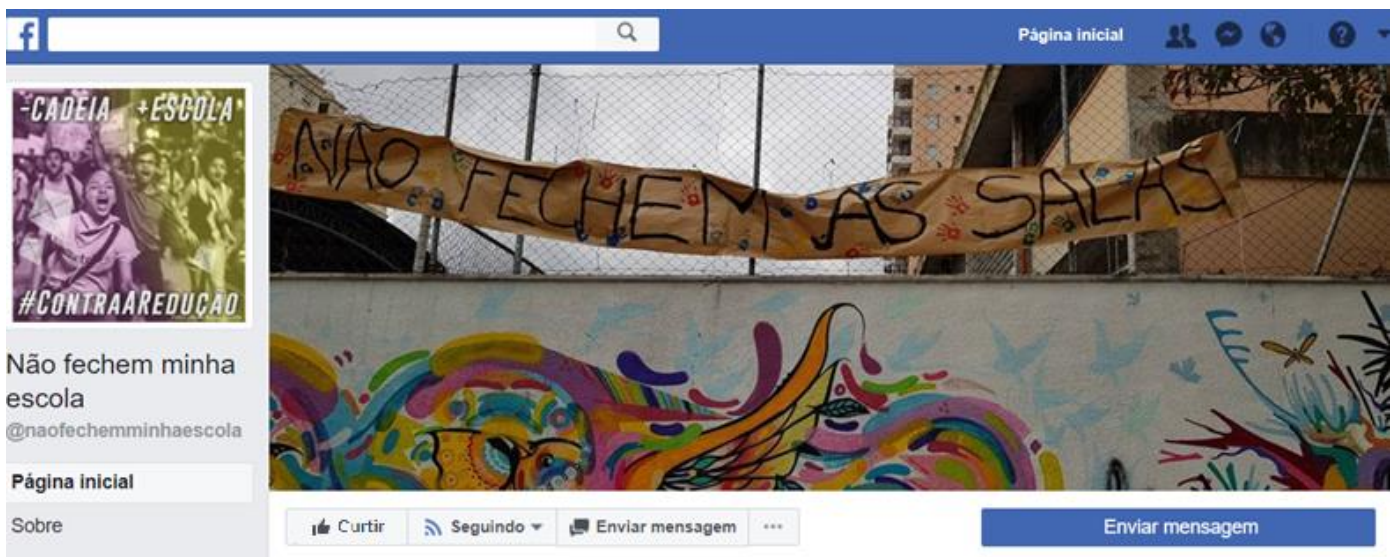

É necessário destacar que, nesse cenário em que a página no Facebook foi formulada, ainda que tentativas de mudança se concretizassem, como a revisão do plano de reorganização educacional de São Paulo, outros projetos de reestruturação educacional

\footnotetext{
13 “'Estudiosos de Bakhtin vêem no conceito de exotopia - que o autor formulou tendo em conta a atividade estética e que perpassa por toda a sua obra -, um elemento-chave para a atividade da pesquisa e a atividade crítica, que se caracterizam, de fato, como ativismo. No contexto da teoria de Bakhtin, atividade (traduzindo a palavra russa deiátielnost), aparece regularmente como o exercício de alguma função, mas sem a idéia de intensidade. Já o termo aktívnost significa "atividade enérgica" dirigida a um objeto, segundo especifica o tradutor de Estética da criação verbal (edição 2003 da Martins Fontes), Paulo Bezerra.” (BORTOLOTTO, 2007).
}

ROHLING, Nívea; REMENCHE, Maria de Lourdes Rossi; BORTOLOTTO, Nelita. Mídias sociais digitais e narrativas de resistência no espaço escolar. Linguagem em (Dis)curso - LemD, Tubarão, SC, v. 18, n. 2, p. 413-429, maio/ago. 2018. 
como a Medida Provisória $746^{14}$, convertida na Lei $n^{\circ}$ 13.415, de 16 de fevereiro de 2017, continuaram em curso e também geraram mais protestos do movimento secundarista. Nesse contexto sócio-histórico, o movimento teve continuidade e, consequentemente, a página não só continuou sendo alimentada, como também agregou novas discussões sobre a atual situação político-social no país como se verifica, por exemplo, na imagem de perfil. Até o fechamento deste artigo a página contabilizou 216.020 seguidores e apresentou 218.235 curtidas $^{15}$. As postagens ocorrem em múltiplas materialidades semióticas e recebem tanto comentários de apoio, como também de repúdio, em algumas situações. No período das ocupações, as notícias eram frequentemente atualizadas na página e eram postados diversos cartazes de manifestações, produzidos no espaço da escola, como apontado neste texto.

A seguir, é apresentada a análise de cartazes de manifestação, representativos das postagens feitas pelos estudantes secundaristas em página do Facebook.

\title{
4 CARTAZES DE MANIFESTAÇÃO: NARRATIVAS POSSÍVEIS?
}

Para a análise aqui proposta dos enunciados do gênero cartazes de manifestações, a noção de cronotopo e esferas discursivas, inscrita na produção teórica do Círculo de Bakhtin, é fundamental. Na visão de Machado (1998, p. 33),

\begin{abstract}
O tempo na teoria do dialogismo não é um constituinte estrutural da narrativa, pelo contrário, a narrativa e, conseqüentemente, os gêneros, são instâncias estéticas de representação do tempo. Visto por esse viés, a noção de tempo distancia-se das abordagens mais divulgadas sobre o assunto, sobretudo porque desconhece as fronteiras entre a ética e a estética.
\end{abstract}

Bakhtin concebe a relação espaço-tempo como processo em contínua formação e está no campo do acontecimento. O tempo que se passa em qualquer espaço não é mero preenchimento espacial, mas é, sobretudo, movimento e transformação. Bakhtin resguarda:

\begin{abstract}
A capacidade de ver o tempo, de ler o tempo no todo espacial do mundo e, por outro lado, de perceber o preenchimento do espaço não como um fundo imóvel e um dado acabado de uma vez por todas mas como um todo em formação, como acontecimento; é a capacidade de ler os indícios do curso do tempo em tudo, começando pela natureza e terminando pelas regras e idéias humanas. (BAKHTIN, 2003[1979], p. 225, grifos do autor)
\end{abstract}

Tudo aponta para o tempo em movimento, desde as manifestações do tempo na natureza (o movimento do sol, das estrelas, o canto dos pássaros, etc.) até as realizações humanas, que configuram as marcas do tempo histórico (a criação das cidades, ruas, obras de arte, técnicas, organizações sociais) (BAKHTIN, 2003).

Ainda, sobre a dimensão espaço-tempo Bakhtin escreve:

\footnotetext{
${ }^{14}$ Disponível em: <http://www.planalto.gov.br/ccivil_03/_Ato2015-2018/2017/Lei/L13415.htm>. Acesso em: 01/03/2017.

${ }^{15}$ Dados retirados da página “Não Fechem minha Escola” no Facebook em 31/10/2017.

ROHLING, Nívea; REMENCHE, Maria de Lourdes Rossi; BORTOLOTTO, Nelita. Mídias sociais digitais e narrativas de resistência no espaço escolar. Linguagem em (Dis)curso - LemD, Tubarão, SC, v. 18, n. 2, p. 413-429, maio/ago. 2018.
} 
As séries espaciais e temporais dos destinos e das vidas dos homens se combinam de modo peculiar, complicando-se e concretizando-se pelas distâncias sociais, que não são superadas. Este é o ponto do enlace e o lugar onde se realizam os acontecimentos. Parece que o tempo se derrama no espaço e flui por ele (formando os caminhos) [...]. (BAKHTIN, 1998, p. 350).

Tal entendimento, como aponta Bortolotto (2007, p. 105), "fornece um ângulo metodológico para a observação da atividade real" seja ela qual seja, porque permite aproximação com a historicidade e nos indica que há "um modo de ver e 'de ler o mundo real', de tornar o mundo das práticas sociais compreensível pelas manifestações mais profundas e sutis das relações e ideias humanas.”.

O cronotopo da estrada, da soleira da porta etc., imagens evocadas por Bakhtin, são significativas e provocativas, pois a concretização do espaço nos indícios do tempo aponta para o tempo da vida humana e para o tempo histórico (BAKHTIN, 1998, p. 355). Imagens cronotópicas constroem cenas no romance, elas nos permitem olhar determinadas produções discursivas contemporâneas e complexas, difusa e fragmentada para então configurar as relações de espaço que se dão nos indícios de tempo, e, desse modo, atribuir sentido aos enunciados.

Machado (1988, p. 35) expõe:

O tempo, para Bakhtin, é pluralidade de visões de mundo: tanto na experiência como na criação, manifesta-se como um conjunto de simultaneidades. A pluralidade de que fala Bakhtin só pode ser apreendida no grande tempo das culturas e das civilizações, quer dizer, no espaço. Eis a síntese teórica que orientou sua abordagem da narrativa com modelo artístico de temporalidades.

$\mathrm{Na}$ análise dos enunciados dos estudantes secundaristas em cartazes, há a provocação de um exercício do olhar para as relações cronotópicas em que os cartazes foram produzidos em um tempo histórico situado, compreendendo-os como narrativas produzidas pelos sujeitos. Os cartazes de manifestação são considerados na sua condição de gênero discursivo, pois se há cronotopo, há gênero do discurso, uma vez que é possível associar o cronotopo a uma situação social de interação, no seio da qual se constituem os gêneros (RODRIGUES, 2001).

Ao observar os embates na esfera escolar e na esfera político-governamental, nesse evento em particular, o espaço da escola foi deslocado não somente pelos projetos de dizer dos jovens estudantes secundaristas, mas também pelos acontecimentos sociais, políticos e pelas possibilidades, na contemporaneidade, de materializar esses projetos discursivos mediante o agenciamento de novas mídias sociais.

Nesse sentido, o espaço escolar marcado historicamente pelo autoritarismo, pela disciplina, pelo controle e, em alguns momentos, visto como um lugar de domesticação de corpos e mentes, mostra-se, nesse evento, como heterogêneo, vivo, pulsante; um lugar de possibilidades de protagonismo juvenil, de narrativas outras. Esse deslocamento da escola como um espaço público heterogêneo e plural se dá, em grande medida, pelo hibridismo entre esferas (escolar e midiática.). É perceptível que o movimento de ocupação da escola se irradia e transborda para outros espaços de manifestação para além dos muros da escola, criando e fazendo circular imagens de resistência política que apontam para mudanças nos modos de ser estudante da escola pública hoje (cronotopias distintas). 
Em uma perspectiva bakhtiniana, é possível afirmar que enunciados e gêneros do discurso não são produzidos em um vácuo social, são, antes de tudo, gerados no interior de determinada esfera de atividade humana e são balizados pelas finalidades de cada esfera. As esferas de atividades humanas são um lugar de coerções e contingências na constituição dos enunciados, que nascem nas interações discursivas; desse modo, elas são moventes, dinâmicas e complexas.

Assim, as esferas sociodiscursivas não são espaços homogêneos. Isso se verifica no caso dos cartazes de manifestação produzidos na ocupação das escolas, pois há um hibridismo entre esferas. A esfera escolar adentra a esfera midiática e produz sentidos outros, ressignificando sobretudo o espaço escolar, mais precisamente a escola pública, como lugar de luta e resistência ao discurso oficial. Nesse sentido, a politização pela luta de resistência aponta para uma imagem cronotópica que se reflete no "crescimento" humano, que abre espaços de atuação e mudanças. Ao mesmo tempo que nascem na situação de manifestação na esfera escolar, tomam as ruas e deslizam para as interações midiáticas sendo replicadas em vários sites, e redes sociais tanto em perfis pessoais como em páginas oficiais. Esse deslizamento produz uma fragmentação desses enunciados sendo difícil situar o espaço de autoria, ou seja, onde o cartaz foi produzido; em qual escola, por qual grupo de estudantes.

\title{
5 ANÁLISE VERBO-VISUAL DOS CARTAZES DE MANIFESTAÇÕES
}

Os cartazes de manifestação foram produzidos no espaço da escola no interior de uma situação interlocutiva específica - a ocupação das escolas públicas. Nesse período de discussão e publicização acerca do movimento de ocupação, os cartazes são, quase que simultaneamente, fotografados e postados em redes sociais. Esse movimento discursivo caracteriza uma imbricada relação de sentidos que se estabelece entre diferentes semioses; entre o signo verbal, que também é imagético, e o visual, imagem postada na tela do computador, mais especificamente numa rede social, como se observa na figura 2:

O cartaz evidencia na escolha estilístico-composicional um processo intertextual com o poema "E agora José", de Carlos Drummond de Andrade. Do ponto de vista estilístico-composicional temos uma paródia do poema "E agora José", de Carlos Drummond de Andrade, exposta como cartaz-protesto, com tom de denúncia do que motivou o movimento estudantil da ocupação e, ao mesmo tempo, com tom de reivindicação de respostas por parte do governador do Estado de São Paulo do que é pleiteado como política do seu governo para o ensino básico.

\author{
A luz apagou \\ A escola ocupou \\ E agora Geraldo? \\ A máscara caiu, \\ A juventude emergiu, \\ A luta explodiu \\ E agora \\ GERALDO?
}

ROHLING, Nívea; REMENCHE, Maria de Lourdes Rossi; BORTOLOTTO, Nelita. Mídias sociais digitais e narrativas de resistência no espaço escolar. Linguagem em (Dis)curso - LemD, Tubarão, SC, v. 18, n. 2, p. 413-429, maio/ago. 2018. 


\section{Figura 2 - Cartaz postado no perfil "Não fechem minha escola"16}

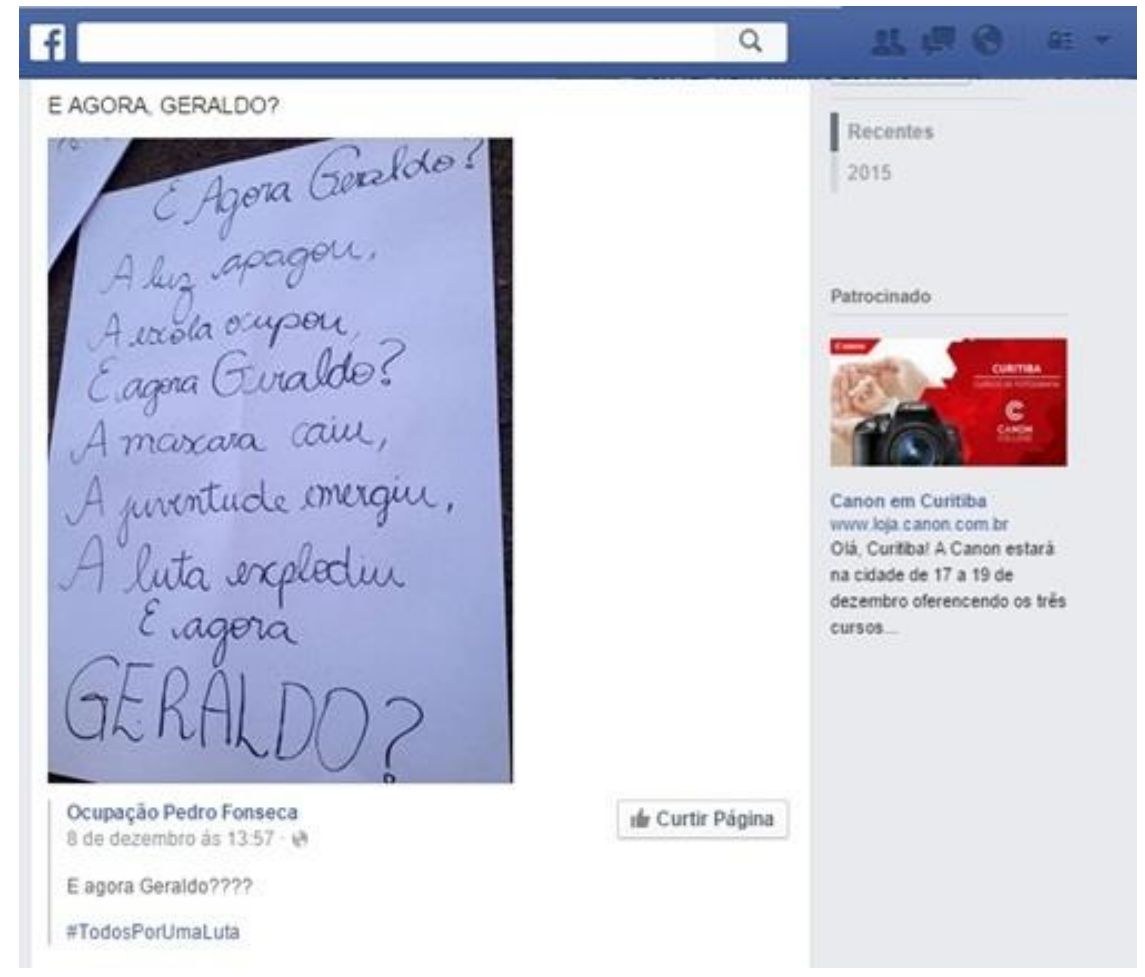

Há a consciência do inusitado diante da tradição da esfera escolar: estudantes passivos, dóceis, cumpridores dos ditames sociais hierárquicos. Há a inversão hierárquica da relação costumeiramente assimétrica na qual o aluno está sempre em uma condição de subordinado a; há a consciência por parte dos estudantes da inversão hierárquica " $A$ juventude emergiu,/ A luta explodiu"/ E agora/ GERALDO?

Ao mesmo tempo que se identifica a letra cursiva, característica das práticas escolares, observamos também que, na linguagem das redes sociais, quando a palavra é grafada em caixa alta é indicativo de elevação da voz. O poema vem grafado na cursiva, contudo, no último verso "E agora GERALDO?" o nome próprio vem grafado em caixa alta, produzindo o efeito de elevação do tom de voz, de um questionamento mais enfático, indicando o enfrentamento no embate que se enuncia. É preciso observar, ainda, que o nome próprio Geraldo remete ao Governador do Estado de São Paulo Geraldo Alckmin.

A análise revela que, em todos os versos, os estudantes cobram de quem lhes cobra a responsabilidade do que está ocorrendo: a quebra do fluxo pedagógico costumeiro, pela ameaça do risco iminente do fechamento de escolas (e do agrupamento delas por níveis de ensino), portanto do direito de acesso à educação pública gratuita e de qualidade. $\mathrm{O}$ modo de se referir à instância governamental por meio de sua representação política, que é alvo do protesto [Governador Geraldo Alckmin], é um aspecto importante, pois nessa enunciação, o objeto de discurso não é referenciado como Governador, mas simplesmente

16 Disponível em: <https://www.facebook.com/naofechemminhaescola/photos/pb.1485355621759400.2207520000.1459982666./1498154713812824/?type=3\&theater $>$. Acesso em: 06/04/16. 
Geraldo. O enunciado é marcado por um tom de enfrentamento e não subserviência (relação de simetria entre as pessoas do discurso). O enunciador se posiciona de modo a ignorar as relações assimétricas, já que se trata do Governador do Estado, chamando-o pelo nome, Geraldo, e acrescenta que "a máscara caiu”.

Do ponto de vista das escolhas lexicais, nesse cartaz, há a menção ao termo 'luta' 'ocupação', fazendo referência ao movimento das ocupações. De modo geral, o termo recorrente nos cartazes foi ocupação, que é extremamente significativo para todo o movimento, que, nesse contexto discursivo, significa uma escola ocupada pelos próprios sujeitos que dela fazem parte, explicitando uma contraposição aos discursos que enunciam que a escola teria sido "invadida" pelos estudantes.

O enunciador, por sua vez, se desvela como a juventude que emergiu. A juventude que discursivamente é tomada como passiva e alienada politicamente. O jovem da escola pública que, não raras vezes, é discursivizado como aquele que não quer estudar e como um aluno indisciplinado. Essa juventude emergiu num processo de luta por seus direitos, portanto, dá mostras de "crescimento", de um movimento de humanização, ainda que essa posição de luta-resistência possa ser contraposta e sua ação de ocupar possa ser repudiada.

De certo modo, esses enunciados conferem a essa juventude um outro lugar, um outro modo de se posicionar como sujeito nesse discurso, um sujeito que se inscreve na luta pela escola pública.

Esse modo de se enunciar e publicizar tais enunciados nas redes sociais digitais vai dando novos contornos à própria esfera escolar, que assume agora um lugar de protagonismo, tornando-se um espaço público importante na discussão de variadas temáticas: etnia, gênero, direitos, democracia ${ }^{17}$. Parece que essa imbricação/hibridismo entre esfera escolar e midiática está produzindo, na escola, uma identidade que deveria ser sua desde sempre, que é a identidade de um espaço público de debate e de pluralidade cultural.

$\mathrm{Na}$ figura 3, mais adiante, na mesma linha do primeiro cartaz analisado, deparamonos com a paródia de alguns versos da letra de uma música, expressa no cartaz-protesto. De modo semelhante, esse cartaz remete também a um "processo intertextual", retomando a música Cálice, de Gilberto Gil e Chico Buarque, produzida no ano de 1973. A escolha desse enunciado para uma paródia por parte dos estudantes é instigante por tratar-se de uma música-protesto, produzida em momento de uma experiência nada positiva da população brasileira com o regime militar, a ditadura, bem como em um tempo tão distante das vivências estudantis atuais. "Pai afasta de mim esse cálice" é parte do refrão da letra da música Cálice e, à primeira vista, tal verso pode ser interpretado como uma referência à agonia de Cristo no calvário. Todavia há um efeito polifônico no uso pelos autores desse tema (calvário de Cristo), bem como em relação à palavra "cálice". Há uma associação entre a palavra escrita "cálice" e outra quando falada "cale-se". Foi o modo de que os autores encontraram para driblar a censura do regime militar implantado no país e, paralelamente, protestar contra a ditadura militar. Provavelmente, conhecedores dessa situação, os estudantes tomam a frente, reacentuando mediante a produção do enunciado "Pai, afasta de mim esse Alckmin" os sentidos da época da ditadura em que a

17 No decorrer das ocupações, eram realizadas palestras e debates envolvendo estudantes, artistas e comunidade sobre variados temas etnia, gênero, democracia, direitos humanos, cultura etc. 
população não tinha de direito se manifestar e nem mesmo de lutar por seus direitos básicos. Analogamente, no período em que a letra da música foi produzida, o conflito e o calvário eram intensos, contudo, no presente e como devir, caso as medidas governamentais instaladas fossem mantidas, os conflitos e as dificuldades seriam grandes também.

Figura 3 - Cartaz postado no perfil "Não fechem minha escola"18

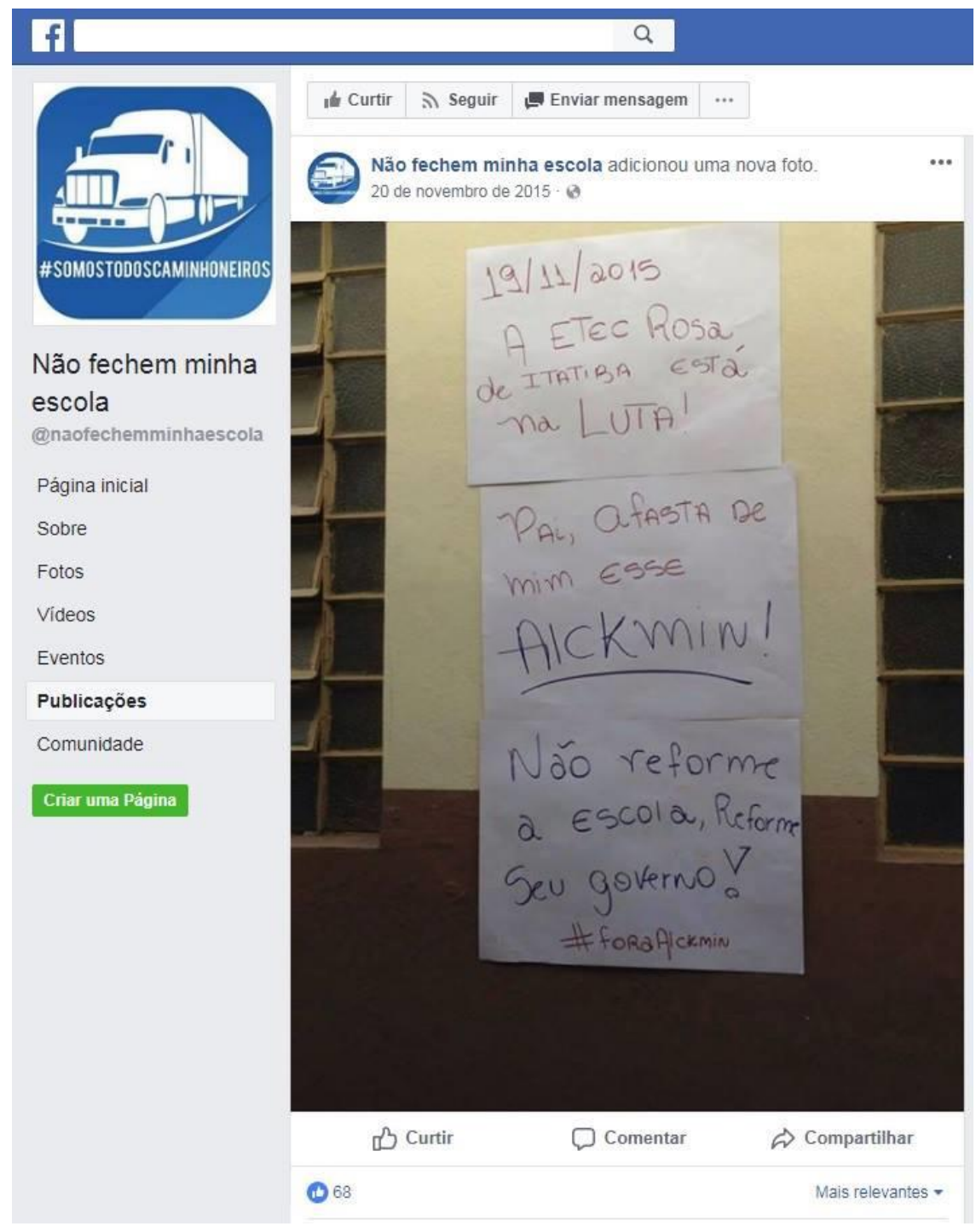

Além disso, o cartaz anuncia que a escola está na luta, ou seja, aderiu ao movimento de ocupação. Novamente verificamos um tom de empoderamento, de força de locução ao enunciar-se de modo diretivo ao seu interlocutor mais imediato, o Governador: "Não reforme a escola, reforme seu Governo!" (manutenção da simetria discursiva).

\footnotetext{
${ }^{18}$ Disponível em:

<https://www.facebook.com/naofechemminhaescola/photos/a.1485520751742887.1073741829.14853556 21759400/1494544354173860/?type=3\&theater $>$. Postado em: 20/11/2105. Acesso em: 28/05/1028.
} 
Outro aspecto importante na composição do enunciado, é a inserção de uma hashtag, que é própria das redes sociais digitais - "\#foraAlckimin". Ao utilizar uma hashtag em um cartaz que seria colado na parede da escola, já havia uma previsão do autor - memória de futuro - de que o cartaz poderia ser fotografado e postado posteriormente nas redes sociais. Ou seja, essas interações compõem outras condições ao gênero discursivo e à sua própria natureza, vão se misturando, hibridizando-se.

Ao inserir uma hashtag no cartaz, é possível dizer que "há um posicionamento valorativo do sujeito, haja vista que, ao utilizar esse recurso expressivo, o interlocutor se apropria de determinado discurso e/ou prática que se relaciona com a hashtag." (RUCINSKI, 2017, p. 87). Assim, para realizar o seu projeto discursivo, o sujeito mobiliza semioses como texto verbal, imagens, cores e especificações próprias das redes sociais, como as hashtags com vistas a destacar a posição valorativa (RUCINSKI, 2017). Vale destacar que a própria escrita, nesse caso, assume um valor imagético específico; tendo em vista que a grafia também é imagem.

Bakhtin (1998) tece considerações quanto à estratificação da língua em relação ao romance e, nesse contexto, traz considerações importantes sobre os gêneros que nos interessam aqui.

\begin{abstract}
Esta estratificação [da língua] é determinada, antes de tudo, pelos organismos específicos dos gêneros. Estes ou aqueles elementos da língua (lexicológicos, semânticos, sintáticos, etc.) estão estreitamente unidos com a orientação intencional e com o sistema geral de acentuação destes ou daqueles gêneros: oratórios, publicitários, gêneros de imprensa, gêneros jornalísticos, gêneros de literatura inferior (como o romance de folhetim, por exemplo) e, finalmente, os diversos gêneros da grande literatura. Estes ou outros elementos da língua adquirem o perfume específico dos gêneros dados: eles se adéquam aos pontos de vista específicos, às atitudes, às formas de pensamento, às nuanças e às entonações desses gêneros. Esta estratificação da língua em gêneros se entrelaça, ora coincidindo, ora divergindo, com a estratificação profissional da língua (em amplo sentido): a linguagem do advogado, do médico, do comerciante, do político, do mestre-escola, etc. Estas linguagens diferenciam-se evidentemente não só pelo vocabulário: elas implicam determinadas formas de orientação intencional, formas estas de interpretação e de apreciação concretas. (BAKHTIN, 1998, p. 96)
\end{abstract}

A análise põe em relevo a subversão da hierarquia costumeiramente assimétrica no espaço escolar, a mobilização de múltiplas semioses e a intertextualidade como recursos para a produção dos efeitos de sentido. Nas produções analisadas, as interações e, consequentemente, os gêneros discursivos borram fronteiras, promovem agenciamentos e hibridizam-se.

\title{
6 CONSIDERAÇÕES FINAIS
}

Neste texto, nosso objetivo foi compreender os sentidos da prática social de criação e circulação de cartazes de manifestação estudantil, postados em um perfil da rede social Facebook intitulado: "Não fechem minha escola", observando-a por domínios da linguagem, mídia e cultura. Os cartazes tematizavam a ocupação das escolas públicas de São Paulo (Brasil) pelos estudantes secundaristas ocorrida em 2015. Buscou-se observar 
como os enunciados, com tonalidade de protesto e resistência, produzem sentidos nesse hibridismo entre esferas discursivas e de que modo apontavam para a construção de outras narrativas de resistência e empoderamento dos estudantes secundaristas no atual contexto político-ideológico da escola brasileira.

A análise pôs em evidência que os cartazes de manifestação hibridizam o espaçotempo da escola, por meio de imbricadas relações de sentido que se estabelecem entre diferentes semioses. Esse modo de enunciar e publicizar que nasce nas escolas e é disseminado nas redes sociais digitais produz novos contornos para a própria esfera escolar, que assume um lugar de protagonismo, constituindo-se em espaço público importante para a discussão de temáticas fundamentais não só para a juventude, mas para toda a sociedade. Esse hibridismo entre esfera escolar e midiática produz, na escola, uma identidade necessária, pois o espaço escolar precisa se constituir em espaço-tempo de encontro, debate e pluralidade de vozes e culturas. Precisa se fortalecer como espaço para (re) criação de narrativas não indiferentes às investidas que ameaçam dar invisibilidade ao outro.

\section{REFERÊNCIAS}

ARAÚJO, J. Reelaborações de gêneros em redes sociais. In: ; LEFFA, Vilson. (Org.). Redes sociais e ensino de línguas: o que temos de aprender? 1. ed. São Paulo: Parábola Editorial, 2016. p. 49-64.

BAKHTIN, M. M. Questões de literatura e de estética: a teoria do romance. Tradução do russo por Aurora Fornoni Bernardini et al. São Paulo: UNESP; Hucitec, 1998 [1975]. [1979]. Estética da criação verbal. Tradução de Paulo Bezerra. 4. ed. São Paulo: Martins Fontes, 2003

Para uma filosofia do ato responsável. Tradução aos cuidados de Valdemir Miotello e Carlos Alberto Faraco. São Carlos: Pedro \& João Editores, 2010 [1986]. 2015. Teoria do romance I: a estilística. Tradução do russo por Paulo Bezerra. São Paulo: Editora 34,

BORTOLOTTO, N. O sentido da ciência no ato pedagógico: conhecimento teórico na prática social. 2007. 239 f. Tese (Doutorado em Educação) - Centro de Ciências da Educação, Universidade Federal de Santa Catarina, Florianópolis, 2007.

CANCLINI, Néstor García. Culturas híbridas. 4. ed. São Paulo: EDUSP, 2013.

GERALDI, J. W. Onde o ético e o estético se encontram hoje. In: CÍRCULO - RODAS DE CONVERSA BAKHTINIANA, 3., 2010, São Carlos. Anais... São Carlos: Universidade Federal de São Carlos, 2010.

HALL, S. A identidade cultural na pós-modernidade. 11. ed. São Paulo: DP\&A, 2006.

MACHADO, I. A. Narrativa e combinatória dos gêneros prosaicos: a textualização dialógica. Itinerários, Araraquara, n. 12, p. 33-46, 1998.

MAGALHÃES, A. S.; QUEIJO, M. E. da S. A arena discursiva das ruas e a condição pós-moderna: da manifestação à metacarnavalização. Bakhtiniana, São Paulo, v. 10, n. 3, p. 166-185, set./dez. 2015.

NÃO FECHEM minha escola. 2016. Disponível em:

<https://www.facebook.com/naofechemminhaescola/photos/pb.1485355621759400.-

2207520000.1459982666./1498154713812824/?type=3\&theater>. Acesso em: 06 abr. 2016.

2017. Disponível em: <https://www.facebook.com/naofechemminhaescola/?fre

$\mathrm{f}=\mathrm{ts}>$. Acesso em: 24 fev. 2017.

RODRIGUES, R. H.. A constituição e o funcionamento do gênero jornalístico artigo: cronotopo e dialogismo. 2001. 347 f. Tese (Doutorado em Linguística Aplicada e Estudos da Linguagem) - Programa de Estudos Pós-Graduados em Linguística Aplicada e Estudos da Linguagem, Pontifícia Universidade Católica de São Paulo, São Paulo, 2001.

ROHLING, Nívea; REMENCHE, Maria de Lourdes Rossi; BORTOLOTTO, Nelita. Mídias sociais digitais e narrativas de resistência no espaço escolar. Linguagem em (Dis)curso - LemD, Tubarão, SC, v. 18, n. 2, p. 413-429, maio/ago. 2018. 
RUCINSKI, V. R. D. Os discursos sobre a identidade docente em espaços de escritas online: valoração e reenunciação discursiva. 2017. 152 f. Dissertação (Mestrado) - Programa de Pós-Graduação em Estudos de Linguagem, Universidade Tecnológica do Paraná, Curitiba, 2017.

SILVERSTONE, R. Por que estudar a mídia? 2. ed. São Paulo: Edições Loyola, 2005.

STAM, R. Bakhtin e a crítica midiática. In: RIBEIRO, A. P. G.; SACRAMENTO, Igor (Org.). Mikhail

Bakhtin: linguagem, cultura e mídia. São Carlos: Pedro \& João Editores, 2010. p. 331-387.

VOLOCHÍNOV, V. N. A construção da enunciação e outros ensaios. São Carlos: Pedro \& João Editores, 2013.

Recebido em: 06/11/17. Aprovado em: 21/05/18.

Title: Digital social media and resistance narratives in the school space

Authors: Nívea Rohling; Maria de Lourdes Rossi Remenche; Nelita Bortolotto

Abstract: The focus of this article is to present the analysis of protest posters that subject a specific discursive-political event: the occupation of public schools in São Paulo (Brazil) by high school students occurred in 2015. It aimed to observe how these utterances, with their protest and resistance tones, produce meaning and build new narratives about being a high school student of Brazilian public schools. The analysis was anchored by Bakhtin Circle's concepts of discourse, utterance, chronotope and evaluative horizon. The results show that, in this particular event, the utterances of the students mark, by the resistance and empowerment tones, the voices of the present that postulate a non-absolute and nondemarcated future. By the living of a social practice that is not indifferent, the utterances prove that students are open to another narrative, which by forms of ideological communication, raising another social horizon, another reality of a collective sphere.

Keywords: Discourse. Media. Public School. Manifestation. Resistance.

Título: Medias sociales digitales y narrativas de resistencia en el espacio escolar

Autoras: Nivea Rohling; Maria de Lourdes Rossi Remenche; Nelita Bortolotto

Resumen: Este artículo focaliza el análisis de afiches de manifestación que tematizan un evento discursivo-político específico, es decir, la ocupación de escuelas públicas de São Paulo (Brasil) por estudiantes secundarios ocurrida en 2015. Observa el modo como esos enunciados, con tonalidad de protesto y resistencia, producen sentidos y construyen nuevas narrativas sobre ser estudiante secundario en la escuela pública brasileña de hoy. El análisis se ancla teórica y metodológicamente en los estudios del Círculo de Bajtín, especialmente en conceptos como discurso, enunciado, cronotopo y horizonte apreciativo. Los resultados muestran que, en ese evento particular, los enunciados de estudiantes secundarios marcan valorativamente, por el tono de resistencia y empoderamiento, voces del presente que postulan un futuro no absoluto y demarcado. Por el vivir de una práctica social no indiferente, se abren para la producción de una narrativa otra, despuntando, por formas de comunicación ideológica, otro horizonte social, otra realidad de ámbito colectivo.

Palabras clave: Discurso. Media. Escuela Pública. Manifestación. Resistencia.

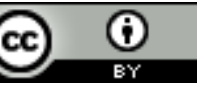

Este texto está licenciado com uma Licença Creative Commons Atribuição 4.0 Internacional.

ROHLING, Nívea; REMENCHE, Maria de Lourdes Rossi; BORTOLOTTO, Nelita. Mídias sociais digitais e narrativas de resistência no espaço escolar. Linguagem em (Dis)curso - LemD, Tubarão, SC, v. 18, n. 2, p. 413-429, maio/ago. 2018. 